\title{
A CRÔNICA NO SÉCULO XIX: AS METAMORFOSES MIDIÁTICAS DE UM GÊNERO LITERÁRIO
}

\section{CHRONIC IN THE NINETEENTH CENTURY: THE MEDIA METAMORPHOSIS OF A LITERARY GENRE}

\author{
Alain Vaillant ${ }^{12}$
}

RESUMO: Este ensaio tem como objetivo responder a questões simples sobre o gênero da crônica no século XIX (do Primeiro Império até as primeiras décadas da Terceira República francesa): qual o seu lugar? Do que é feita? Qual é sua função cultural e ou política? Que imagem possui?

PALAVRAS-CHAVE: Crônica. Gênero literário. Século XIX.

\begin{abstract}
This essay aims to answer simple questions about the genre of chronicle in the nineteenth century ( from the First Empire until the first decades of the Third French Republic) : What is its place? What is it made of? What is its cultural or political function? What image does it have?

KEYWORDS: Chronicle. Literary genre. Nineteenth century.
\end{abstract}

\footnotetext{
${ }^{1}$ Artigo traduzido por Pablo Simpson.

2 Directeur du CSLF (Centre des sciences de la littérature française).
} 


\section{A CRÔNICA NO SÉCULO XIX: AS METAMORFOSES MIDIÁTICAS DE UM GÊNERO LITERÁRIO}

A história da crônica no século XIX exibe o mais extraordinário paradoxo. Em muitos aspectos, a crônica surge incontestavelmente como a forma textual que melhor encarna a nova cultura midiática e que, retrospectivamente, parece ser dela o mais perfeito emblema textual. À medida em que avançamos pelo século, ela se impõe como um gênero maior da escrita jornalística, ilustrado pelas assinaturas dos maiores escritores, que não hesitam em reunir posteriormente as suas crônicas em livros. No entanto, na maior parte do tempo, a "crônica" permanece uma realidade inconstante e variada; não se reduz a uma forma genérica estável ou claramente descritível e, aliás, quase nunca reivindica, a não ser de modo alusivo ou indireto, o nome de "crônica".

Para os contemporâneos, a "crônica" possui, portanto, o estatuto invejável de uma realidade familiar cujos contornos estão condenados, apesar disso, a permanecerem vagos ora porque julguemos inútil torná-los ainda mais precisos, ora porque estimemos a crônica, enfim, indigna desse esforço de clarificação. O lugar que lhe dedica Pierre Larousse em seu Grand Dictionnaire universel $d u$ XIXe siècle (1866-1876) ${ }^{3}$ é exemplar dessa estranha presença-ausência da crônica. No artigo "bate-papo" [1868], o redator, com tom de troça jornalística frequente aos colaboradores do dicionário, atacando o "furor" da crônica - ou prestando-se ao trocadilho fácil que autoriza a palavra, sugere uma doença "crônica": "A crônica é, na hora em que escrevemos, uma raiva, um furor, uma doença. Se a crônica é realmente uma doença, queira Deus, a despeito do jogo de palavras, que ela não seja... crônica". Mas o leitor, que se dirige ao artigo " crônica », constata que, em meio a 35 colunas quase exclusivamente consagradas às crônicas medievais e suas variantes, a crônica jornalística é despachada com uma fórmula lapidar: "artigo de jornal onde se encontram fatos, novidades do dia, barulhos da cidade". Segue uma breve enumeração onde vê-se, ademais, que a crônica de imprensa nunca é considerada absolutamente, em si mesma, porém acompanhada por um adjetivo que deve especificá-la e justificá-la: "crônica política, crônica parisiense, crônica teatral, crônica musical, crônica artística, crônica financeira”.

\footnotetext{
${ }^{3}$ Pierre Larousse, Grand Dictionnaire universel du XIXe siècle, Paris, Larousse, 1866-1876.
} 
A concepção essencializada da crônica, que faria dela uma realidade, de fato, midiática e reconhecida como tal, independentemente de suas aplicações temáticas, deve ser buscada noutro lugar: ou no artigo "bate-papo", sob o modo satírico que acabamos de ver, ou no artigo "cronista". Neste caso, mesmo que seja dito muito hiperbolicamente, na abertura, que "de todos os vocábulos de nossa língua, a palavra cronista é talvez aquela de mais difícil definição", a notícia do dicionário não deixa de prestar uma vibrante homenagem a cronistas cujo papel, comparável àquele que se arrogava Balzac em La Comédie humaine, seria o de serem historiadores do tempo presente ou, ao menos, acumular materiais para futuros historiadores: "São eles [os cronistas] que, na realidade, rabiscam as memórias da nação. [...] Nossos futuros Michelet os consultarão com proveito". Tudo se passa como se, por efeito de um curioso deslocamento, o mérito da crônica não viesse de sua forma textual, mas da nova espécie de escritores-jornalistas que ela fez surgir e que os redatores do Grand Dictionnaire universel estão propensos a apoiar tanto mais por serem estes, em sua maioria, ou terem sido, cronistas de imprensa.

O objetivo que me proponho é, portanto, esquecer a maneira com que, retrospectivamente, pensamos e construímos a crônica do século XIX, com o risco de proceder por amálgama ou por extrapolação, e responder a estas questões simples: face à longa duração do século (do Primeiro Império até as primeiras décadas da Terceira República), qual o lugar exato da crônica? Do que ela é feita? Qual é sua função cultural e ou política? Que imagem ela possui?

Para responder a isso, sondei os jornais de época, como sempre somos obrigados a fazer com esse material literalmente infinito e inapreensível da imprensa periódica: apresentarei as respostas seguindo um plano grosseiramente cronológico, que permitirá acompanhar a evolução e, por assim dizer, o desenvolvimento da "crônica": de início identificada com uma simples rubrica (sob o Império e a Restauração), esta vai se impor com a monarquia de Julho como um estilo antes de se constituir, de fato, como gênero no Segundo Império. Meu trabalho se inscreve, assim, no prolongamento da síntese já proposta por MarieÈve Thérenty, em La Civilisation du journal (2011, p.953-968), e confirmará com frequência suas análises - modulando-as ou nuançando-as, às vezes, em função da perspectiva mais precisa que adoto aqui: a das relações entre literatura e cultura midiática.

\section{A RUBRICA "CRÔNICA"}

Comecemos com uma curiosidade lexicológica. Apesar de suas deficiências, o Grand Dictionnaire universel du XIXe siècle possui ao menos o mérito de ser o único a registrar o sentido jornalístico da palavra "crônica". De fato, todos os dicionários anteriores (Dictionnaire de l'Académie, Dictionnaire de la conversation et de la lecture de William Duckett, 1832) atêm-se ao sentido historiográfico tradicional: crônica, "história redigida seguindo a ordem dos tempos". A edição de 1835 do Dictionnaire de l'Académie toma mesmo o cuidado de especificar, sem dúvida porque a ciência histórica está, então, em plena renovação e não deve ser confundida com essas narrativas arcaicas: "trata-se de certas histórias escritas antigamente". Os mesmos dicionários ainda acrescentam, invariavelmente, um exemplo particular, a "crônica escandalosa", isto é, ainda segundo o Dictionnaire de l'Académie, os "os maus ruídos, os discursos caluniosos", dando a entender que essa crônica, ao contrário da crônica histórica, prende-se a fatos secundários e costumes, embora considerados exclusivamente pelo lado ruim. Será preciso esperar o Dictionnaire de la langue française de Émile Littré, em 1872, para que as duas significações da velha crônica estejam claramente distintas, sem mais nenhuma nota pejorativa: de um lado, "anais conforme a ordem dos tempos", e, de outro, "o que se diz de pequenas novidades correntes". 
De fato, os desenvolvimentos da crônica midiática seguem exatamente essas duas orientações semânticas: a crônica é ora o registro dos fatos do dia-a-dia, ora o registro dos fatos mais banais.

O primeiro sentido é, notadamente, aquele que se impõe todas as vezes que, num periódico, a palavra "crônica" é especificada por um adjetivo que torna preciso o conteúdo temático (crônica literária, teatral, musical, etc.); acrescentemos que este é, ainda hoje, o sentido mais usual nas publicações periódicas, e de longe. É frequente que uma revista, generalista ou especializada, comporte uma rubrica "crônica" que mencione, para o período correspondente ao ritmo da publicação, todos os acontecimentos que mereçam ser assinalados, ao lado dos artigos de fundo que constituem a substância principal da revista. Ora, vê-se de imediato o problema que impõe a adoção do nome "crônica" pela imprensa cotidiana: um jornal, cuja função é dar conta o mais exatamente possível da atualidade, é, por natureza, uma "crônica". É por isso que nos jornais, mesmo cotidianos, as crônicas são quase sempre semanais - como se precisassem de uma distância temporal mínima para destacar-se do elo imediato que implica a cotidianidade. Parece, de modo geral, que entre o ritmo do cotidiano, feito para a atualidade, e aquele mensal, mais apropriado ao trabalho da síntese e de soma que opera uma revista, a semana seja a medida temporal ideal para instaurar essa "proximidade à distância" buscada pela crônica, diferentemente da lógica informativa do jornal.

Assim, por um fenômeno de dissimilação que inverte curiosamente o sentido e a função da "crônica", a crônica do jornal passa a designar um espaço textual onde o escriba escolhe afastar-se da realidade, destacar-se do curso do tempo, permitindo-se uma espécie de vagabundagem temática conforme a sua inspiração. $O$ que leva ao segundo sentido da "crônica" histórica: uma rubrica que trata de coisas comuns, não tendo necessariamente um elo estreito com o fio da atualidade dos eventos, porém voltada prioritariamente aos costumes, isto é, aos comportamentos privados ou às práticas sociais. É a esse sentido que se dirige a palavra "crônica", empregada de modo absoluto, e de que se tratará a partir de agora. É um lugar comum, desde o século XIX, remontar a voga da crônica aos artigos sobre os costumes parisienses que Étienne de Jouy publica na Gazette de France e que reúne em volume, a partir de 1812, sob o título de L'Hermite de la Chaussée d'Antin, ou observations sur les mours et les usages français au commencement du XIXe siècle. No entanto, Jouy não utiliza em nenhum momento o termo "crônica". Em contrapartida, em 1814, o Journal de l'Empire (título provisório do Journal des débats) propõe, por exemplo, uma "Pequena crônica de Paris" (essencialmente teatral e cultural); em 1817, um grupo de literatos publica a Revue ou chronique parisienne, politique, morale, littéraire et théâtrale; a ela se segue uma Chronique de Paris ou le spectateur moderne, enquanto, no mesmo ano, o Mercure de France oferece igualmente a seus leitores uma sessão "Crônica". Durante os anos 1820, a "crônica" toma um grande número de jornais: encontramo-la, por exemplo, em L'Écho du soir, Le Pirate, Le Grondeur, Le Compilateur, com a aparência frequente de uma sucessão de notícias breves, prefigurando as listas de variedades ou variedades de Paris, mais ou menos divertidas ou de caráter narrativo, que encherão os jornais da monarquia de Julho.

Esse primeiro apanhado nos leva a uma primeira observação acompanhada de dois comentários. Para começar, está bem claro que, desde o final do Primeiro Império e durante toda a Restauração, a crônica, cultural e social, alcança um franco sucesso junto a leitores de jornais e que ela já está perfeitamente instalada na paisagem midiática. No entanto, e este será meu primeiro comentário, não concluamos rápido demais tratar-se de uma precoce modernidade da imprensa francesa. Na realidade, a causa primeira, principal, imediata, dessa prosperidade da crônica é simplesmente a censura que pesa sobre o que é impresso, a impossibilidade de falar diretamente dos assuntos importantes - evidentemente, das questões políticas. A crônica é, aliás, inicialmente, um derivativo imaginado pelo poder para distrair e 
seduzir indiretamente - por assim dizer, de forma subliminar - o público. Retornemos a Étienne de Jouy, que é tudo menos um jornalista comum. Na imprensa do Primeiro Império que foi brutalmente nacionalizada por Napoleão I, ele é o "censor", encarregado de examinar todos os artigos do jornal Le Publiciste, absorvido pela Gazette de France em 1811: ele é o homem da direção da Librairie, portanto, o representante do ministério do Interior, e é nesse sentido que lança seus "boletins dos costumes", chamados ainda de "boletins da situação de Paris". Um e outro título evocam os "boletins do Grande Exército"; lembram-nos de que, no momento em que o Império está sucumbindo na guerra da Espanha e passa, além disso, por uma grave crise econômica, a primeira função dessas crônicas é oferecer uma imagem apaziguada e feliz de Paris - com Étienne de Jouy jamais se esquecendo, em seus artigos, de destilar elogios a todas as iniciativas imperiais. Sob a Restauração, um pouco menos repressiva, a lógica se inverte: a crônica serve a difundir, de modo bem suave e indireto, um discurso silenciosamente contestatório. O caráter aparentemente menor e leve da crônica lhe serve, então, de anteparo para uma escrita menos contida: após 1815, Étienne de Jouy prossegue, então, sua carreira de jornalista, mas, a partir daí, como figura celebrada da oposição liberal. De todo modo, não esqueçamos essa verdade primordial, que vale para crônica tanto quanto para o folhetim: no século XIX, o cultural é sempre a máscara ou o substituto do político.

Isso não impede - e esse será meu segundo comentário — que a crônica responda a uma verdadeira demanda cultural, ligada às transformações profundas da sociedade francesa pouco após a Revolução. Implicitamente ou, de modo mais frequente, explicitamente, a crônica é sempre a crônica "de Paris", uma vitrine aberta para a cidade capital cuja vitalidade urbana fascina. Evidentemente, havia o precedente do Tableau de Paris [1781] de Mercier, várias vezes citado, e sobretudo o modelo do Spectator de Addison e de Steele [1711-1712], que oferecera à Londres seu primeiro espelho midiático. Mas, na França do século XIX, onde as todas dinastias parecem estar desde então em suspenso e onde as evidências religiosas estão definitivamente abaladas, Paris surge como o primeiro grande mito moderno - e um mito tão poderoso que irá se impor durante mais de um século ao conjunto do mundo ocidental. Como todo mito, ele vale menos por si mesmo do que pelo que simboliza com um extraordinário brilho - a saber, a emergência dessa "civilização urbana" que, frente ao avanço das classes médias burguesas, transtorna progressivamente todos os modos de representação, cuja versão ficcional e popular será oferecida, trinta anos mais tarde, pela voga internacional dos mistérios urbanos, na trilha dos Mystères de Paris de Eugène Sue (18421843).

Ao fim desse primeiro itinerário, que nos levou até 1830 - isto é, à revolução de Julho e ao estabelecimento do liberalismo político e econômico — podemos concordar com esta dupla constatação: 1/ A era midiática está estreitamente relacionada com a civilização urbana em vias de se impor na Europa industrializada e da qual, na França, Paris concentra todo o prestígio, embora o mito de Paris e a cultura do jornal surjam numa perpétua elaboração recíproca. 2/ Em sistemas institucionais nos quais a liberdade de expressão permanece ainda bastante limitada, a crônica de costumes [i.e., essencialmente, a crônica de costumes parisienses] é a forma, historicamente datada, que assume a representação midiática dessa civilização urbana.

\section{O ESTILO "CRÔNICA"}

Entretanto, de forma incontestável, uma nova etapa foi alcançada sob o reino de Louis-Philippe, encarnação gentil dessa burguesia que, com ele, chegou ao poder: mais do que nunca, o espírito da crônica triunfa na imprensa que, laureada por seus combates políticos, converte-se à cultura e ao divertimento. Marie-Ève Thérenty vê mesmo em 
Delphine de Girardin, escritora e egéria do jornal La Presse, criado em 1836, "a que funda, de fato, o gênero da crônica, oferecendo-lhe seus códigos e estratégias" (THÉRENTY, 2011, p.957). Mas, de seu modo de escrever, encontraríamos sem dúvida equivalentes nos artigos de Balzac ou de Gautier e, de modo mais geral, nos principais fornecedores de historietas ou anedotas divertidas da "pequena imprensa". Na verdade, é toda a cultura midiática da época que parece coletivamente envolvida numa verve de cronista cujas três principais características trata-se agora de precisar:

1) Em novembro de 1844, La Chronique, "revista do mundo fashion", é rebatizada como Chronique de Paris. Pois, decididamente, não há crônica digna desse novo que não seja crônica parisiense e, no momento em que se desenvolvem as indústrias do divertimento, as modas de vestuário, os produtos de luxo e os bens de consumo de todo tipo, a crônica tem as feições de um interminável artigo publicitário - multiplicado, recopiado, rescrito de jornal em jornal. Para além dos processos anedóticos da publicidade indireta e clandestina, que permite aos jornalistas monetizar seus talentos, a crônica, encarregada de exaltar com todos os tons os encantos da capital, tem no início uma função econômica: ela acompanha a revolução industrial e comercial pela qual passa a França, com todas as transformações sociais que induz; favorece-a graças às técnicas de comunicação que inventa e aperfeiçoa continuamente em função de suas necessidades. Na mesma época, o prodigioso desenvolvimento da literatura panorâmica, oferecendo a visão caleidoscópica da vida moderna através das coleções de livrinhos agradáveis e frequentemente ilustrados, pode ser considerada como um efeito desse jornalismo da crônica parisiense. Ou, de fato, o contrário: a crônica não é senão uma das formas midiáticas no seio dessa atividade incessante e multiforme de autorrepresentação que permite à Paris impor a sua imagem - em seguida, eventualmente, rentabilizá-la, através das múltiplas representações que oferecerem dela de modo quase sincronizado os jornais de província e, sobretudo, a imprensa estrangeira.

2) O próprio objeto da crônica - Paris, cidade de todas as seduções — parece lhe impor o seu estilo: um estilo espirituoso, feito de leveza, ironia - como se vê ainda hoje na França na maior parte das rubricas culturais da imprensa ilustrada. É esse estilo, com as qualidades literárias que ele supõe, que faz o sucesso de todos os jornalistas reputados pelas fórmulas, a presença de espírito, uma capacidade de segundo grau e a insinuação debochada - numa palavra, tudo o que se supõe constituir a quintessência do parisianismo. Consideradas de maneira global, a letra e o espírito da crônica se resumem a uma retórica da ironia e a uma ética de uma não-seriedade que se explicam, uma e outra, por seu contexto comunicacional. De um lado, a crônica deve se distinguir e busca distrair dos artigos políticos que ocupam o melhor lugar nos jornais e aos quais é reservada uma eloquência ampla e grave. De outro, a ironia the confere uma espécie de legitimidade que lhe permite melhor exercer o papel que lhe é reservado, o de um fazer-valer bom tanto para o próprio jornal quanto para Paris, de que constitui a vitrine sorridente: sabemos bem que o riso é um das técnicas de base da comunicação publicitária.

3) Esse estatuto ambivalente da crônica - igualmente prático para a moda e produto de consumação corrente - explica que o termo mesmo não apareça quase nunca no momento em que o espírito da crônica triunfa na imprensa. Se Delphine de Girardin o empregasse para designar seus folhetins no jornal La Presse, ela saberia que isso desvalorizaria sua própria produção. É a razão porque o evita cuidadosamente, do mesmo modo que não o encontramos nenhuma vez em La Comédie humaine de Balzac, pretensamente interessado em oferecer a representação mais completa da sociedade de seu tempo. Em contrapartida, assim como Balzac publica, desde 1830, "Cartas de Paris" (essencialmente políticas), este é também o título do "Correio de Paris" que Delphine de Girardin atribui a seus textos de La Presse: nem contamos, aliás, sob a Restauração e a monarquia de Julho, as cartas de todos os tipos, quase sempre ficcionais, que publicam os jornais. Os verdadeiros modelos que inspiram nesse 
momento a atividade da crônica são os da carta ou da conversação. Ora, as referências a essas práticas mundanas trazem uma dupla vantagem: não apenas inserem a crônica na grande tradição da eloquência privada (por definição, livre e desinteressada), mas acenam para a cultura aristocrática - como revela o pseudônimo adotado por Delphine de Girardin: o "visconde de Launay". Concluo: existe certamente, em todos os jornais, um estilo da crônica que causa furor em toda Paris midiática; mas o gênero está ainda por nascer.

\section{O GÊNERO "CRÔNICA"}

O gênero, chegamos enfim a ele, nasce propriamente após 1850, sob o Segundo Império, e, como já está dotado de seu estilo e de um grupo de jornalistas experimentado, nasce, por assim dizer, já totalmente armado, como Atenas da cabeça de Júpiter. A "crônica", à qual se concede enfim o título, difunde-se por toda a imprensa, para tornar-se essa "doença crônica" que aparenta denunciar o Grand Dictionnaire universel, em 1868. Os escritores que buscam entrar na literatura trilham quase todos o caminho da crônica. Não apenas porque é preciso ganhar a vida mas também, como escreverá saborosamente Maupassant à sua mãe em 3 de abril de 1878, na medida em que a crônica permite "tomar de tempos em tempos um acontecimento interessante e desenvolvê-lo com reflexões e dissertações ao lado" "4 dito de outro modo, exercer a função de jornalista mas renunciando o menos possível à fantasia de sua inspiração.

Passemos rapidamente pelas causas conjunturais dessa explosão da crônica - elas são capitais mas nos interessam menos aqui. A razão principal, exatamente como sob o Primeiro Império, é o retorno brutal de uma censura asfixiante, que expulsa a liberdade de expressão política do jornal, esvazia as rubricas sérias de seus conteúdos, empurra a escrita livre para rubricas secundárias - isto é, como sempre, as rubricas culturais. Mas os escritores, formados pela prática irônica do jornalismo da monarquia de Julho, aprenderam a arte da alusão e da expressão indireta. Além disso, a crônica, que é uma forma textual maleável, compressível ou extensível, muito fragilmente formatada, presta-se particularmente às práticas pouco profissionalizadas da "pequena impressa", dessa imprensa literária onde encontram refúgio todos os escritores da boêmia ${ }^{5}$ (cripto-republicanos, intelectuais de oposição, poetas escandalosos, marginais de todo tipo). Nesse contexto, a crônica se torna igualmente o emblema do jornalismo "paratópico" ${ }^{6}$ ou dissidente, e o signo do reconhecimento de uma tribo literária cuja marginalidade anuncia a reivindicação de autonomia. A leveza espiritual se enche de derrisão, violência, ou mesmo de franca amargura. Nos últimos anos do Império, é ainda nas colunas da crônica (quando têm por autor um Vallès ou um Rochefort) que se experimenta e se desenvolve a oposição a Napoleão III: e daí a homenagem que lhe rendia o dicionário do muito republicano Pierre Larousse. Enfim, mesmo Paris, aonde acaba chegando toda crônica, não é mais a capital imprudentemente alegre do Courrier de Paris de Delphine de Girardin: a cidade da festa imperial, transformada pelas obras de Haussmann, esconde uma cidade mais tenebrosa - a dos subúrbios, da prostituição noturna, do protesto operário, da miséria social —; as avenidas desenhadas em La Vie parisienne têm o outro lado, La Rue de Vallès; a Paris mundana dos cronistas da grande imprensa se avizinha de Le Spleen de Paris de Baudelaire - do qual duas séries de poemas

\footnotetext{
${ }^{4}$ A correspondência de Maupassant foi editada por Jacques Suffel em 1973 para o Cercle du bibliophile. Ela está hoje disponível online no endereço http://maupassant.free.fr/corresp1.html.

${ }^{5}$ Sobre a relação entre boêmia e pequena imprensa, ver Les Bohèmes, 1840-1870, anthologie réalisée et annotée par Jean-Didier Wagneur et Françoise Cestor, Seyssel, Champ Vallon, 2012.

${ }^{6}$ Sobre a noção de paratopia, ver Dominique Maingueneau, Le Discours littéraire. Paratopie et scène d'énonciation, Paris, Colin, 2004.
} 
em prosa são publicados justamente em agosto de 1862 em La Presse, antigo jornal de Delphine de Girardin.

A evocação de Baudelaire não é aqui fortuita. O poeta das Fleurs du Mal é também o autor de uma espécie de crônica, "A moral do brinquedo", que foi publicada em Le Monde littéraire do 17 de abril de 1853, de onde se extraiu posteriormente, numa versão reescrita e condensada, O brinquedo do pobre do Spleen de Paris. Ora, essa evolução, do artigo de jornal ao poema em prosa, ilustra perfeitamente as novas potencialidades formais da crônica ${ }^{7}$. Evidentemente, a maior parte dos cronistas permanecem tão tagarelas, leves, conversacionais, superficiais quanto antes - já que a função principal deles continua sendo, no interior dos jornais que os acolhem, a de assegurar o preenchimento a baixo custo. No entanto, no meio dessa massa profusa, uma minoria de textos se aproxima de um modelo genérico, de um tipo ideal que eles executam com mais ou menos êxito mas que, pouco a pouco, vai modificar o estatuto da crônica.

O essencial se deve a uma tendência de fundo que ultrapassa, e de muito longe, a escrita jornalística: a crônica se aproveita da chegada à maturidade da estética realista, que se impõe a toda cultura moderna, tanto nos jornais quanto em literatura ou em pintura, e onde o essencial não é mais o domínio artístico (a elegância ou a expressividade da frase, para o escritor), mas a representação do real: não o bem dizer, mas a aptidão a ver o mundo e a figurar essa visão para o leitor, graças a uma prosa tanto densa quanto o mais possivelmente sugestiva: nesse sentido, a irritabilidade violenta de um Vallès, a um só tempo agressiva e elíptica, permanece como um modelo insuperável. Essa poética da escrita, cujo domínio artístico de Flaubert e dos Goncourt marca o sucesso do romance, conduz também a uma nova estética midiática, onde a arte da descrição, mesmo narrativizada, torna-se a pedra de toque da prosa do jornal; a crônica tende ao poema em prosa, conforme praticado por Baudelaire, cujos textos oferecem igualmente, numa tonalidade globalmente irônica, um esboço tomado do momento e um julgamento sobre o mundo.

Uma tal artealização (artialisation) permite também pôr à distância os modelos tomados à eloquência privada. Quando interpela o seu leitor, o cronista exibe e encena, desde então, seu estatuto de autor e de narrador-descritor. E mesmo se a crônica se baseia numa estrutura dialógica, como nos textos de Alphonse Allais, o esquema conversacional é totalmente integrado ao jogo irônico instituído pelo humorista. Em todo caso, o cronista, mesmo através das formas mais concisas e no modo menor que é o seu, impõe sua voz e sua visão do mundo, segundo os mecanismos de subjetivação que caracterizam a modernidade literária. Nesse nível de sofisticação, a crônica soma-se à arte nova, ou sobretudo aparece como uma novidade cuja literariedade não precisaria, para que pudesse ser reconhecida como tal, da interposição da ficção. Todo o encanto da crônica reside, então, na articulação de uma representação sugestiva de uma realidade qualquer, o mais frequentemente sem relação direta com a atualidade imediata, e de uma presença autoral que exprime com aforismos, apreciações surpreendentes, comentários empáticos ou irônicos. Sob a pluma de Maupassant - em sua correspondência e nos seus textos publicados —, sentimos bem, aliás, que a noção de "crônica" perdeu toda consistência e que ela oferece um sinônimo cômodo à palavra conveniente de artigo - ou, ao menos, de artigo escrito por um escritor ${ }^{8}$.

No extremo fim do século, na Revue de Belgique de 15 de novembro de 1896, Franz Mahutte resume assim o gênero da crônica: “(...) ela se afasta da informação; toma, na verdade, como tema, um fato, um acontecimento, um fato do dia-a-dia, mas esse fato isolado e sem pertinência, esse fato árido e insignificante, ela o apresenta de modo vantajoso, veste-o

\footnotetext{
${ }^{7}$ Sobre essa relação entre crônica jornalística e poema em prosa, ver notadamente a tese de Fanny Bérat, Les Origines journalistiques du poème en prose, Université Charles de Gaulle-Lille 3, 2006.

${ }^{8}$ Essas precisões a respeito de Maupassant me foram dadas ao longo de várias conversas eletrônicas com Antonia Fonyi e Marlo Johnston, aos quais agradeço aqui.
} 
com tecidos agradáveis, tece nele belas cores que dissimulam a aridez! Em seguida, vai mais longe do que o fato que comenta: amplifica-o, dá a ele uma forma e o generaliza. Numa época em que mal se tem tempo de ler com a cabeça repousada, traz-nos correndo e sem acentuar mais do que o necessário, uma ponta de literatura e de filosofia". Independentemente do tom de escárnio, Mahutte tem absoluta razão. O gênero da "crônica", ao chegar a seu pleno florescimento literário, não tem de "crônica" senão o nome, tendo perdido todo elo real com o curso do tempo que ela se encarregava de relatar. Paradoxal mudança de situação: a crônica "literária" da Idade Média guardava meticulosamente o registro dos acontecimentos, como a mídia atual; a crônica jornalística do século XIX, por sua vez, adquire pleno reconhecimento, mas separando-se de sua função de informação. Nesse meio caminho entre cultura midiática e legitimidade literária, ela parece condenada a um perpétuo jogo duplo, a uma dupla marginalidade, que lhe impõe, de onde se vire, uma espécie de dissidência textual. Com todas as seduções formais que extrai de uma estética da brevidade pacientemente aperfeiçoada ao longo do século XIX, ela figura a má consciência literária da mídia — a não ser que isso não seja má consciência midiática da literatura.

Tradução de Pablo Simpson (UNESP/Ibilce)

\section{REFERÊNCIAS}

DUCKETT, William. Dictionnaire de la conversation et de la lecture, Paris, Belin, 1832.

LAROUSSE, Pierre.Grand Dictionnaire universel du XIXe siècle, Paris, Larousse, 18661876.

LITTRÉ, Émile. Dictionnaire de la langue française, Paris, Hachette, 1863-1872.

THÉRENTY, Marie-Ève. "La chronique" in La Civilisation du journal. Histoire culturelle et littéraire de la presse française au XIXe siècle, Dominique Kalifa, Philippe Régnier, MarieÈve Thérenty e Alain Vaillant (org.), Paris, Nouveau Monde éditions, 2011, p. 953-968.

Recebido em: 09 de julho de 2015.

Aceito em: 29 de julho de 2015. 